\title{
Intervirology
}

Altmann, A. 123, 160

Berg, T. 102

Braun, P. 102

Brudney, D. 172

Camacho, R.J. 179

Däumer, M. 102

De Wolf, H. 138

Eberle, J. 79, 102, 128

Ehret, R. 102

Esser, S. 167

Fätkenheuer, G. 147, 154

Garcia, A. 172

Geretti, A.M. 172

Gürtler, L. 79, 128

Häussinger, D. 147, 154, 167

Hower, M. 154

Incardona, F. 123

Jensen, B. 167

Johnson, M. 172

Kaiser, R. 102, 123, 147, 154, 160, 167

Kleinkauf, N. 102
Klimkait, T. 118

Knechten, H. 147, 154

Korn, K. 102

Kücherer, C. 102

Lavee, T. 123

Lengauer, T. 108, 113, 123, 147, 154

Liu, T.F. 98

Luebke, N. 167

MacCartney, M. 172

Marshall, N. 172

Mc Kenna, P. 138

Müller, H. 102

Nauwelaers, D. 138

Noah, C. 102

Obermeier, M. 102

Oette, M. 147, 154, 160

Pattery, T. 138

Peres, Y. 160

Pfister, H. 154

Pironti, A. 102

Prosperi, M. 123

Reinheimer, C. 134
Reuter, S. 147, 154

Rockstroh, J.K. 147

Rosen-Zvi, M. 123, 160

Schülter, E. 123, 160

Shafer, R.W. 98

Sierra-Aragón, S. 84

Smith, C. 172

Sönnerborg, A. 123, 160

Struck, D. 160

Stürmer, M. 102, 134

Tang, M.W. 98

Thielen, A. 102, 113

Van Baelen, K. 138

Van Houtte, M. 138

Verlinden, Y. 138

Villacian, J. 138

Vitiello, P. 172

Walter, H. 84, 102

Wolf, E. 102

Zazzi, M. 123, 160

\section{Subject Index Vol. 55, No. 2, 2012}

454 sequencing 113

AIDS 79, 179

Algorithms 128

Antiretroviral therapy 84, 123

- treatment 167

Assays 134

Bioinformatic interpretation system 108

Clinical validation 102

Coreceptor usage 113

Drug efficacy 160

- resistance $84,128,134$

- - interpretation 118

- - mutations 98

- tolerability 172

EuResist 160

Genetic factors 79

Geno2pheno 118

Genotype 113

Genotypic resistance 98

- testing 108

- tropism test 172
- $\quad$ resistance 102

Genotyping 134, 138

Highly active antiretroviral therapy 154 , 160

HIV 79, 113

- late presenter 147

- replication inhibition 84

- resistance 108,123

- transmission 147

- tropism 108

HIV-1 98, 118, 123, 134, 147, 167, 172

- group O 128

- resistance testing 138

HIV-2 128

- drug resistance 179

- treatment management 179

HIV-GRADE 102

Immune reconstitution 147

Interpretation system 123

Linear regression modelling 138

Machine learning 123
Maraviroc 118, 172

Mutations 134

Online resource 98

Personalized therapy 167

Phenotypic testing 108

Phenotyping 138

Primary drug resistance 154

Protease inhibitors 138

Quasispecies 79

Resistance 123

- mutations 138

- prevalence 154

Retroviral targets 84

Reverse transcriptase inhibitors 138

Salvage 167

Selection pressure 79

T cell activation 172

Treatment switch 160

Tropism 113

XTrack system 118 